\title{
Nurses Wellbeing and Primary Nursing: The Experience of the Emergency Surgical Ward in the General Hospital in Piacenza
}

\author{
Nicastro Mario, Liguori Paolo, Mozzarelli Fabio* \\ General Hospital G. Da Saliceto Piacenza (Italy), Local Health Authority, Piacenza, Italy
}

Email address:

fabio.mozzarelli@gmail.com (M. Fabio)

${ }^{*}$ Corresponding author

\section{To cite this article:}

Nicastro Mario, Liguori Paolo, Mozzarelli Fabio. Nurses Wellbeing and Primary Nursing: The Experience of the Emergency Surgical Ward in the General Hospital in Piacenza. Science Journal of Clinical Medicine. Vol. 8, No. 6, 2019, pp. 61-65. doi: 10.11648/j.sjcm.20190806.11

Received: September 20, 2019; Accepted: October 21, 2019; Published: December 16, 2019

\begin{abstract}
The growing complex of organizations and the new demand for people's health care lead to a planned and personalized care solution. Primary nursing (PN), is a new model of care focused on the people to be treated and, at the same time, restores responsibility, autonomy and role to the nursing staff. The study was based on an analysis of the wellbeing climate following the implementation of the PN in emergency surgical ward in the General Hospital in Piacenza. In the emergency surgery ward of the General Hospital Guglielmo Da Saliceto in Piacenzathe results of organization remodulation and model of care are being analyzed. In this job the observations are been focussed on wellbeing of nursing staff. The Mc Closkey Mueller Satisfaction Scale (MMSS) is used for the study before and after the change, The Team Climate Inventory (TCI), used after thepractices changes and the staff satisfaction survey after the implementation of PN. At the beginning, with the MMSS methods, the results show impatience with some contractual and remunerative aspects; instead, after the introduction of the PN, the results show a satisfaction for teamwork, the interaction between the team personnel and with patients. Similarly, it alsoincreases the perception of the degree of autonomy of contribution in decision making and in the authoritativeness of the role covered. The new assistance model also shows good results from TCI and Focus Group to achieve the goals of assistance and organization. The increased satisfactions of the nursing staff show a better quality care.
\end{abstract}

Keywords: Assistance, Primary Nursing, Organizational Wellbeing, Satisfaction, Change

\section{Introduction}

The increased complexity of healthcare organizations and of the health conditions of the people assisted in care facilities, lead the organizational systems and the nursing staff to analyze own work and to find adequate solutions to provide appropriate and functional answers to the needs of assistance.

These new conditions pull to the renewal of practices and the changing becomes an essetial condition for organizations and professionals [1].

In recent years, the evolution of care and organizational models has focused on the care methods that put people and their needs at the center, re-proposing the fundamental role of care and giving nurses the responsibility of taking care of and protecting them from your clients [2-5].
On this way, the emergency surgery ward of the Local Health Unit (LHU) in Piacenza, in which a structural and organizational reorganization was recently implemented, it was decided to use this opportunity to renew the care processes going towards the application of the primary nursing (PN) model, starting with the newly formed emergency surgery unit that saw the light in October 2018.

The PN, bases its roots on the need to change the paradigm of the care focus: the patient is at the center of the nurse's care.

It is clear that the fundamental aspects are the construction of relationships with one's own clients [6], the role of the reference nurse recognized as the primary nurse who holds the responsibility for the cases assigned to him emerges, the assistance is focused on the problems detected on the individual patients and addressed through care planning 
involving all team members, such as associate nurses, support staff and all other professionals involved in the care process [7].

The above approach would allow nurses to achieve a high degree of satisfaction in what are their favorite autonomy and independence with assistance is geared towards continuity and comprehensive global customization.

This model also allows to have an overall and integrated vision of the care pathway from reception to discharge and at the same time, it allows the nurse to fully act on his own competence and to be recognized and valued [8]. According to the conception of Marie Manthey, creator of the model, the PN can represent the return to the central point of nursing, to the heart of the nursing care modernly understood [9].

The main premises are the construction of relationships and the personalized planning of assistance.

The realization of an effective relationship requires a continuous and positive interaction between the nurse and the patient and the energy derived from this dynamic connection brings results to the agreement.

The PN is a model to identifies the problems for the referent nurse, which he shares with the patient and/or family member, defines objectives and related result indicators, chooses the most suitable ways to implement the plan and monitors the evolution towards the expected results.

It is considered a conceptualization that aims at a better quality of care, guaranteeing a higher level of patient wellbeing and higher working satisfaction of nurses.

In the study conducted at the emergency surgery ward in the Guglielmo Da Saliceto Hospital in Piacenza, which was the subject of the implementation of the PN model, the organizational climate and the perception of the change towards the aforementioned model by the nursing staff.

In this regard, two separate investigations were carried out.

The first of cross sectional observational type in before/after mode [10] in which the climate of the operating unit before and after the change of the care model was investigated through the McCloskey Mueller Satisfaction Scale (MMSS).

A further study was conducted after the implementation of the PN through the team climate inventory (TCI) questionnaire and finally a focus group meeting was held on the welfare modalities.

The statistical analyzes were processed with the Microsoft office excel 2007 version software, considering the central trend measurements, the percentiles and the statistical significance test, the chi framework considering it significant if equal to or less than 0,05 .

\section{Methods}

The evaluation of organizational well-being has been implemented through the Mc Closkey Mueller Satisfaction Scale which is a validated tool both in terms of content [11, 12] and in terms of translation into Italian [13].

It was compiled anonymously in compliance with the privacy regulations and the processing of personal data with the authorization of the Piacenza local health authority.

The MMSS, aims to investigate the satisfaction of the staff with respect to their work and the context in which it takes place.

The survey consists of 31 items with the possibility of expressing one's opinion through a Likert scale from 1 to 5 points where the value 1 indicates the maximum dissatisfaction while the value 5 represents the maximum level of satisfaction.

The survey was proposed to all the nurses of the emergency intervention unit before/after in which the first evaluation was carried out in October 2017 on the ordinary hospitalization staff, where most of them were transferred to the new ward of emergency surgery.

The second investigation was offered to the staff of the latter operating unit and was carried out in January 2019.

The team climate inventory questionnaire [14] in the Italian language adapted version [15] consists of 44 elements divided into three sections.

The first area is represented by the aspects of communication and innovation, consisting of 26 questions relating to the internal climate understood as a human and professional relationship with work colleagues.

The second part concerns the objectives and consists of 11 items that require a subjective assessment of the work organization aimed at identifying the objectives that can be achieved as individuals and /or in collaboration with the group.

The last dimension focuses on the work style through 6 questions concerning the collaboration between the nursing staff.

Also in this case the questionnaire was filled in anonymously and it was requested to assign to each article a value between 1 and 5, in which 1 indicates the maximum disagreement while the value 5 represents the maximum agreement.

The TCI was administered only in the post-implementation in order to assess the stabilization of the change occurred and to verify in detail the relationships between the members of the organization.

To get the impressions as much as possible narrated by the professionals involved in the implementation of the PN model, in March 2019 a focus group meeting was created, which identifies a sample of nurses belonging to the emergency surgery ward.

The comparison took place in a reserved area, sufficiently large and bright in the presence of an conductor and an observer who used an audio recording.

The questions proposed to the participants were taken from the proceedings of the 57th National Congress of the Italian Society of Geriatrics and Gerontology [16].

\section{Results}

Regarding the before/after survey through the MMSS, the two groups compared did not show statistically significant differences in terms of sex, age, length of service and basic training.

In the first part of the survey or between articles 1 to 11 , we find questions relating to contractual institutions such as the use of holiday leave, the wage level, the opportunity to divide part-time and others.

In this session, the satisfaction of the interviewees between 
the pre and post evaluation is mostly aggravated, with the the flexibility of the planning of the weekend and the exception of the voices concerning the use of the holidays, incentive for the festive work (figure 1).

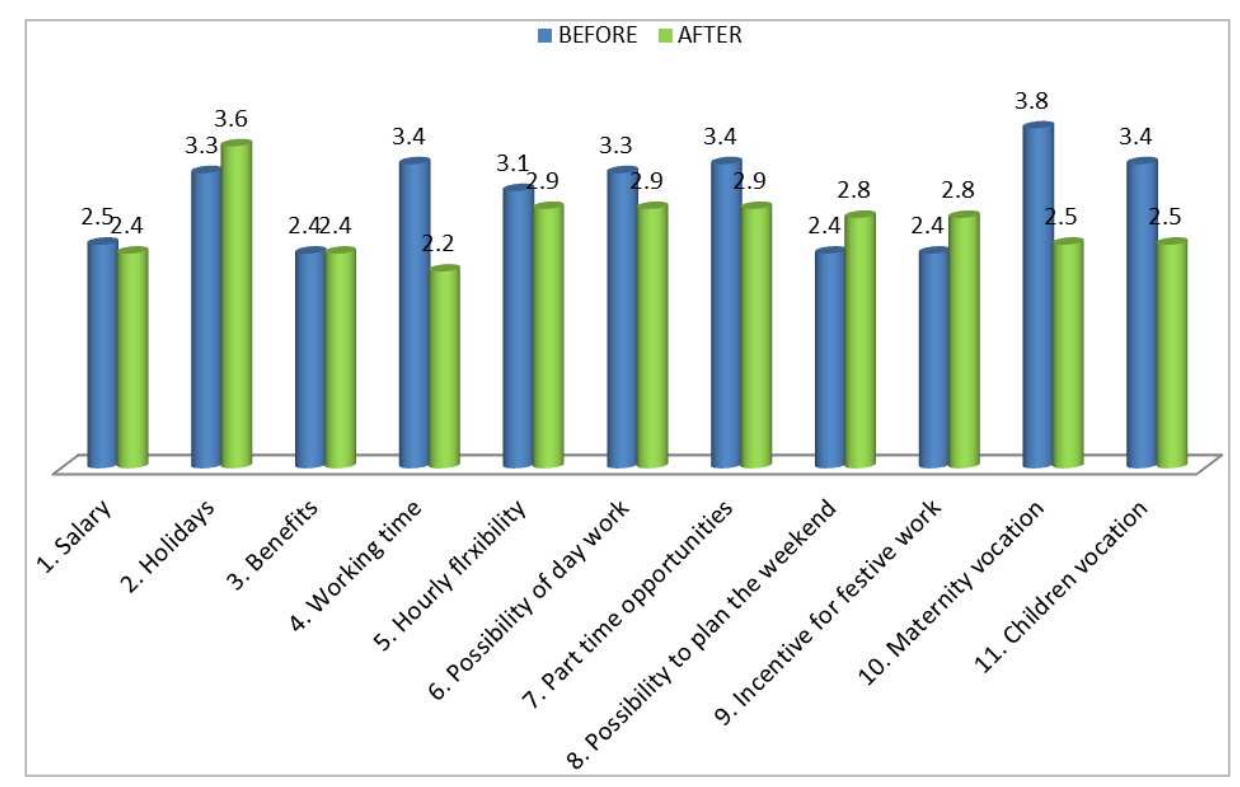

Figure $1.1^{\circ}$ CHAPTER contractual rules.

In the second part of the survey, which goes from question 12 to 31 , which describes in detail the contextual aspects of the organizational climate of the group to which it belongs, a clear improvement was registered in all the articles that give a good working atmosphere with the peaks satisfaction with the relationship with doctors, assistance methods, recognition by superiors and colleagues, opportunities for updating and research, and the possibility of making organizational decisions (figure 2).

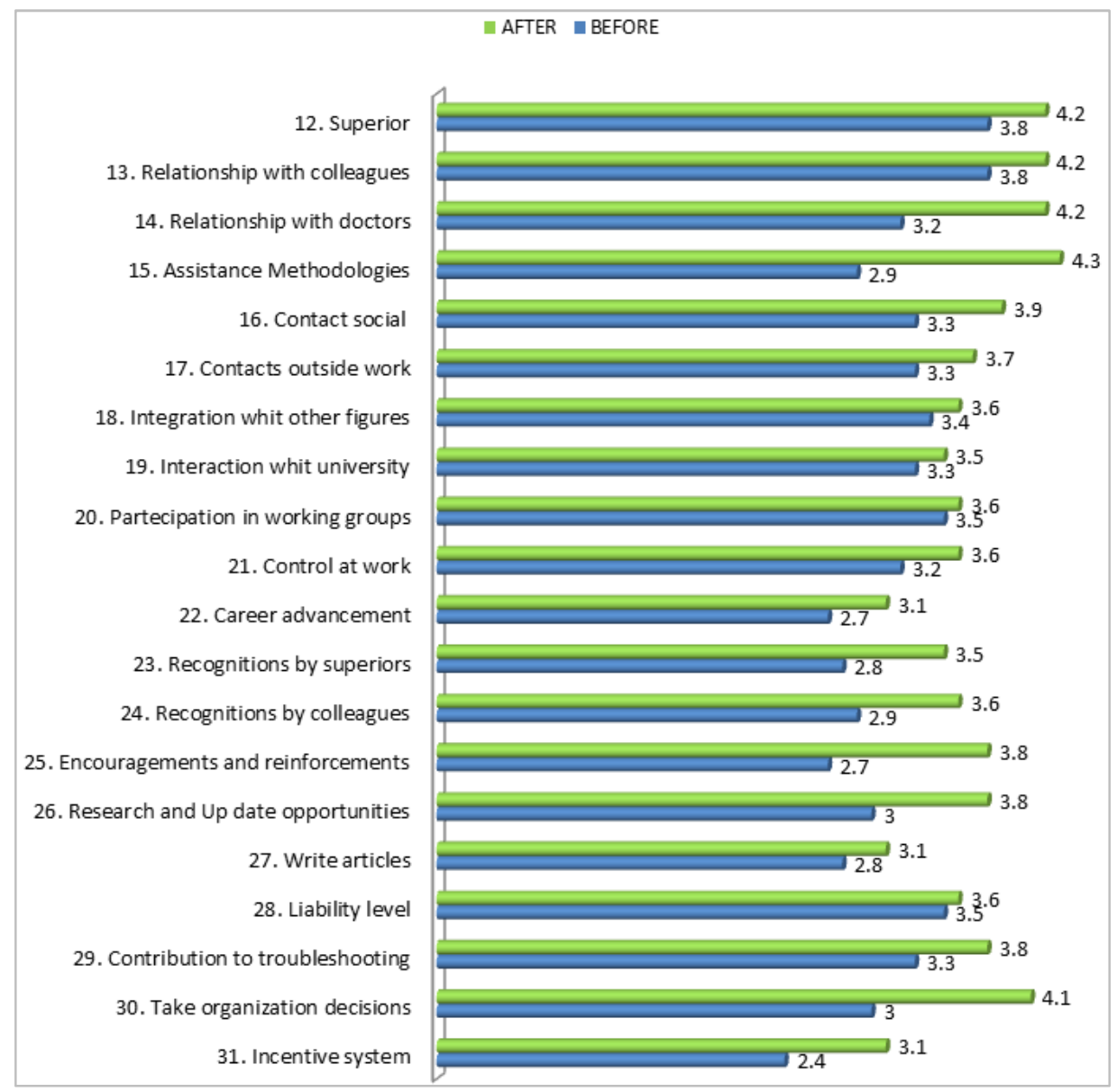

Figure 2. $2^{\circ}$ CHAPTER internal climate. 
The first part of the TCI, is composed of 26 questions and is also expressed with a Likert scale in which the minimum level of agreement corresponding to the value 1 while the maximum agreement is represented by the number 5 .

In the first item, the respondent staff is invited to express their thoughts on the level of communication of the team.

From the analysis of the results it emerges the highest average of the scores assigned by the nurses is referred to the sharing of information with the group with a result of 4.4 points, the development of new ideas has totaled 4.1 points, the cooperation between the group for the development of new ideas to a score of 4 , the same result regarding the sharing of information on work topics and the sharing of resources for the development of new ideas.

The second part of the questionnaire consists of 11 items related to the objectives of the work.

The results that emerged with higher scores, concerned the utility and appropriateness of the objectives with 3.6 points, the value attributed to the objectives themselves with an average of 3.9 and how worthy of attention they are, reaching a value of 3.6.

The last seven questions were focused on collaboration between colleagues and on the performance of the activities.

Three items totaled the same score or 3.2 points related to the interest in reaching high level standards, the capacity for critical discussion of the practices in use and the use of new ideas proposed by the group.

The main positions were initially identified and later categorizations were carried out to provide representativeness of the opinions.

For the question: $<<$ how satisfied are you with the new welfare / organizational model? $>>$, the responses showed a high level of satisfaction especially in relation to the working methods prior to the change.

For the second question: <<according to your experience, is the clinical care path shared with the patient, family and /or caregiver? $>>$, the responses involved a high degree of involvement through the participation of the nurse in the conversation between family members and doctors, but also on other occasions, for example during the delivery to the patient's bed and at any time in which it was necessary to interact with them.

For the third question: $<<$ do you think this model favors the continuity of care? $>>$, the responses showed attention to the continuum between patient, family, nurses and doctors as an appropriate way to keep the patient at the center of wellbeing of the clinical project.

For the fourth question: $<<$ do you have the feeling of working in a team? $>>$, the perception of working in a group with the sharing of organizational and clinical assistance objectives emerges, it shows that there is a general care taken in the patient and not fractional and performative as in other work experiences carried out by the participants.

And again: <<back to a traditional welfare model? $>>$, unanimously, none of the participants would like to return in the most absolute way to organizations oriented to carrying out tasks for activities and tours.

For the sixth question: $<<$ in a scale of values from 1 to 5 where the latter represents the maximum satisfaction, what is your level of professional well-being at the moment? $>>$, on this topic the majority expressed itself on values between 4.5 and 5 points with respect to the methods of well-being, returning a very high level of professional satisfaction to the sample in question.

For the last question in question: $<<$ from the moment that you apply this model do you feel more accomplished professionally? $>>$, the group reports to be significantly more professionally realized thanks to the acquisition of greater autonomy, consideration, involvement, support and with a greater authority of role.

Respondents say that the satisfaction achieved in the workplace also has a positive impact on the personal sphere.

\section{Considerations}

The analysis of organizational well-being in the new emergency surgery ward of the General Hospital Guglielmo Da Saliceto in Piacenza has developed in three different ways.

First of all, Mc Closkey Mueller Satisfaction Scale was administered of satisfaction of the seller, in two phases, in the period of pre-implementation of the organizational and welfare change based on the primary care model and subsequently the same investigation was proposed again after the transformation.

Between the first and the second survey some differences emerge: in the initial evaluation there is an intolerance with respect to some general areas such as remuneration, the possibility of resorting to permits and facilitations, flexibility in working hours.

In view of these aspects considered unsatisfactory, in the second observation, we note a better level of interaction between team members, a greater appreciation of the new ways of well-being, a significant recognition by other team professionals, a more effective opportunity to acquire skills through training and research and the possibility of being better considered in organizational decisions.

As in the case described, also in other experiences, the implementation of the PN led to a good level of satisfaction among the assistance personnel $[17,18]$.

This was also confirmed by the analysis of the results collected through the TCI questionnaire administered in the post implementation, in which a high level of satisfaction was perceived, as this model leads to a greater involvement of the team, guaranteeing better collaboration and communication among staff to achieve the set targets [19].

In the focus group, among the participants it is noted that the new model of care is highly appreciated, especially if referred to the previous treatment modalities, it also shows a greater interaction with the patient and his reference persons.

With the application of these new welfare modalities, the interviewed nurses feel more autonomous, more involved and 
considered and also a higher level of authority.

The strengths of the change made can be ascribed to the analysis from different points of view of the change made while a limit concerns the applicability that can be traced back only to the specific context of the emergency surgery department of the Piacenza hospital.

\section{Conclusions}

The organizational change implemented in the surgical area of the Piacenza LHU, considered a re-modulation of the welfare model, moving towards the centrality of the patient and the personalization of care.

In the complex spheres more than anything else they deal with providing services to people, the task and the well-being of the professionals is a central theme that must be increasingly considered.

The experience described in this analysis states how the well-being and satisfaction of the staff allows us to achieve excellent and take care of our professionals so that they are effectively effective taking care of their clients.

\section{References}

[1] Rebora, G., \& Minelli, E. (2007). Change Management. Come vincere la sfida del cambiamento in azienda. Milano, Italy: Etas libri.

[2] Barelli, P., Pallaoro, G. \& Peroli S. (2006). Modelli di organizzazione dell'assistenza: sono efficaci? Assistenza Infermieristica \& ricerca, 25 (1): 35-41.

[3] Butel, M., Collins, R., Drennan J., et al. (2011). Hospital nurse staffing models and patient and staff-related outcomes. Cochrane Database Syst Rev. 6; (7): CD007019.

[4] Hoffart, N. \& Woods, CQ. (1996). Elements of a nursing professional practice model. J Prof Nurs, 12 (6): 354-64.

[5] Nissen, JM., Boumans, NP. \& Landeweerd J. (1997). Primary Nursing and quality of care: a Dutch study. Int J Nurs Stud, 34 (2): 93-102.

[6] Payne, R. \& Steakley, B. (2015). Establishing a primary nursing model of care. Nurs Manage 46 (12): 11-3.

[7] Kusk, KH. \& Groenkjaer, M. (2016). Effectiveness of primary nursing in the care and satisfaction of adult inpatients: a systematic review protocol. JBI Database System Rev Implement Rep. 14 (6): 14-22.
[8] Mattila, E., Pitkänen, A., Alanen, S., et al. (2014) The Effects of the Primary Nursing Care Model: A Systematic Review. J Nurs Care, 3 (6): 1-12.

[9] Manthey, M. a cura di Costazza, G. Galetti, P. Misko-Kelling, M. (2008). La pratica del Primary nursing. L'erogazione dell'assistenza basata sulle relazioni e guidata dalle risorse. Roma, Italy: Il pensiero scientifico.

[10] Dal Molin, A., Gatta, C., Boggio Gilot, C., et al. (2018). The impact of Primary Nursing care pattern: results from a before - after study, J Clin Nurs. 27 (5-6).

[11] Tourangeau, AE., Mc Gillis Hall, L., Doran, DM., Petch, T. (2006). Measurement of nurse job satisfaction using the McCloskey/Mueller Satisfaction Scale. Nurs Res, 55 (2): 12836.

[12] See SE., Dahinten, SV., Mac Phee, M. (2016). Psychometric evaluation of the McCloskey/Mueller Satisfaction Scale. J Nurs Sci, 13 (4): 487-495.

[13] Taddia, P., Chiari, P., Calanchi, S., et al. (2007). Valutazione della soddisfazione per l'organizzazione basata sulla valorizzazione di posizioni funzionali tra gli infermieri del PoliclinicoS. Orsola-Malpighi. AIR 26;(4): 210-218.

[14] Anderson, N. \& West, MA. (1998). Measuring climate for work group innovation: development and validation of the team climate inventory. J. Organiz. Behav, 19: 235-258.

[15] Ragazzoni, P., Baiardi, P., Zotti, AM., et al. (2002). Italian validation of the Team Climate Inventory: a measure of team climate for innovation. Journal of Managerial Psychology, 17: 325-336.

[16] Mongardi, M. (2012). Il modello di intensità di cura: le ricadute e gli esiti sugli operatori. Atti $57^{\circ}$ Congresso Nazionale della Società Italiana di Geriatria e Gerontologia. Milano.

[17] 'Temmi, M., Mecugni, D., Vezzani, E., et al. (2017). Il Primary Nursing un modello applicato, cronaca di un'esperienza di implementazione in due strutture complesse ospedaliere. L'infermiere 5: 38-43.

[18] Ferrua, R., Gatta, S., Croso, A., et al. (2016). The impact of primary nursing model on cultural improvement: a mixedmethodstudy. Creative nursing 22 (4): 259.

[19] Hollerman, G., Poot, E., Mintes- De Groot, J., et al. (2009). The relevance of team characteristics and team strategies in the implementation of nursing innovations: a literature review. Int j nurs stud 46 (9): 1256-1264. 